\title{
Molecular Dynamics Simulations for Effects of Fluoropolymer Binder Content in CL-20/TNT Based Polymer-Bonded Explosives
}

\author{
Shenshen Li and Jijun Xiao*
}

check for updates

Citation: Li, S.; Xiao, J. Molecular Dynamics Simulations for Effects of Fluoropolymer Binder Content in CL-20/TNT Based Polymer-Bonded Explosives. Molecules 2021, 26, 4876. https://doi.org/10.3390/

molecules26164876

Academic Editor: Weihua Zhu

Received: 8 July 2021

Accepted: 9 August 2021

Published: 12 August 2021

Publisher's Note: MDPI stays neutral with regard to jurisdictional claims in published maps and institutional affiliations.

Copyright: (c) 2021 by the authors. Licensee MDPI, Basel, Switzerland. This article is an open access article distributed under the terms and conditions of the Creative Commons Attribution (CC BY) license (https:/ / creativecommons.org/licenses/by/ $4.0 /)$.
Molecules and Materials Computation Institute, School of Chemistry and Chemical Engineering, Nanjing University of Science and Technology, Nanjing 210094, China; lishenshen91@163.com

* Correspondence: xiao_jijun@njust.edu.cn; Tel.: +86-139-5198-3026

\begin{abstract}
In order to better understand the role of binder content, molecular dynamics (MD) simulations were performed to study the interfacial interactions, sensitivity and mechanical properties of 2,4,6,8,10,12-hexanitro-2,4,6,8,10,12-hexaazaisowurtzitane/2,4,6-trinitrotoluene (CL-20/TNT) based polymer-bonded explosives (PBXs) with fluorine rubber $\mathrm{F}_{2311}$. The binding energy between $\mathrm{CL}$ 20/TNT co-crystal $\left(\begin{array}{lll}1 & 0 & 0\end{array}\right)$ surface and $\mathrm{F}_{2311}$, pair correlation function, the maximum bond length of the $\mathrm{N}-\mathrm{NO}_{2}$ trigger bond, and the mechanical properties of the PBXs were reported. From the calculated binding energy, it was found that binding energy increases with increasing $\mathrm{F}_{2311}$ content. Additionally, according to the results of pair correlation function, it turns out that $\mathrm{H}-\mathrm{O}$ hydrogen bonds and $\mathrm{H}-\mathrm{F}$ hydrogen bonds exist between $\mathrm{F}_{2311}$ molecules and the molecules in CL-20/TNT. The length of trigger bond in CL-20/TNT were adopted as theoretical criterion of sensitivity. The maximum bond length of the $\mathrm{N}-\mathrm{NO}_{2}$ trigger bond decreased very significantly when the $\mathrm{F}_{2311}$ content increased from 0 to $9.2 \%$. This indicated increasing $\mathrm{F}_{2311}$ content can reduce sensitivity and improve thermal stability. However, the maximum bond length of the $\mathrm{N}-\mathrm{NO}_{2}$ trigger bond remained essentially unchanged when the $\mathrm{F}_{2311}$ content was further increased. Additionally, the calculated mechanical data indicated that with the increase in $\mathrm{F}_{2311}$ content, the rigidity of CL-20/TNT based PBXs was decrease, the toughness was improved.
\end{abstract}

Keywords: CL-20/TNT co-crystal; fluoropolymer binder; interactions; mechanical properties; polymerbonded explosives (PBXs); molecular dynamics (MD) simulation

\section{Introduction}

High-performance and insensitive explosives are always the target of researchers in the field of energetic materials [1-4]. However, high performance and safety are somewhat mutually exclusive for current single compound explosives, which seriously limits their development and applications [5,6]. Among well-known commercially available singlecompound explosives, 2,4,6,8,10,12-hexanitro-2,4,6,8,10,12-hexaazaisowurtzitane (CL-20) is the most famous high energy density compound [7], which features high density and high detonation velocity but fails to meet the important safety requirements due to its high sensitivity [8]. Contrasting with CL-20, 2,4,6-trinitrotoluene (TNT) has different features in many ways [9-12], including low oxygen balance, modest detonation velocity, economical production costs, and low impact sensitivity, but energy density is relatively low. Fortunately, the method of producing co-crystals offers a practical solution to improve certain properties of energetic materials such as oxygen balance, sensitivity, detonation velocity, and safety [13-15]. Bolton [16] prepared co-crystal of CL-20/TNT in a 1:1 molar ratio, which exhibits lower sensitivity than CL-20, and has closed detonation performance and oxygen balance to CL-20.

The combination of explosives with polymeric binders to form polymer-bonded explosives (PBXs) was an important advancement in high-explosives science, offering improved 
safety and reliability, while maintaining performance [17-19]. Based on those advantages, PBXs are widely applied in many defense and economic scopes. A lot of experimental research $[8,20]$ and theoretical studies [21-23] on energetic composite materials including PBXs are drawing more and more attention in recent decades. Not only can PBXs reduce the impact and friction sensitivity of explosives in PBXs [24,25], but they also have good physical and mechanical properties of polymers [26,27] and hence can be produced and used safely and conveniently.

Due to a balance of chemical and mechanical properties with processability when mixed with explosives, fluoropolymers emerged as commonly used binder [28]. To estimate the effect of the polymer binders on the co-crystal-based PBXs, we select fluoropolymer $\mathrm{F}_{2311}$ as the polymeric binder in CL-20/TNT based PBXs, which is a random copolymer made up of vinylidenedifluoride (VDF) and chlorotrifluoroethylene (CTFE) with the molar ratio of 1:1, showed in Figure 1a.

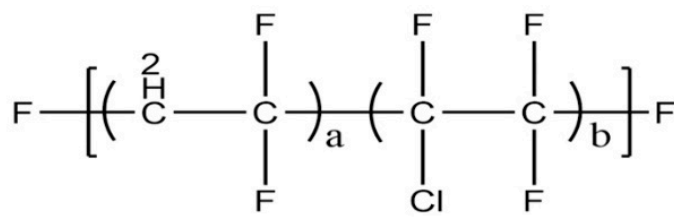

(a) $\mathrm{F}_{231}$

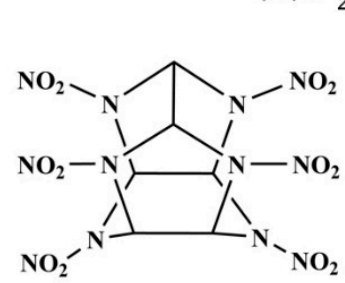

(b) $\mathrm{CL}-20$<smiles>Cc1c([N+](=O)[O-])cc([N+](=O)[O-])cc1[N+](=O)[O-]</smiles>

(c) TNT

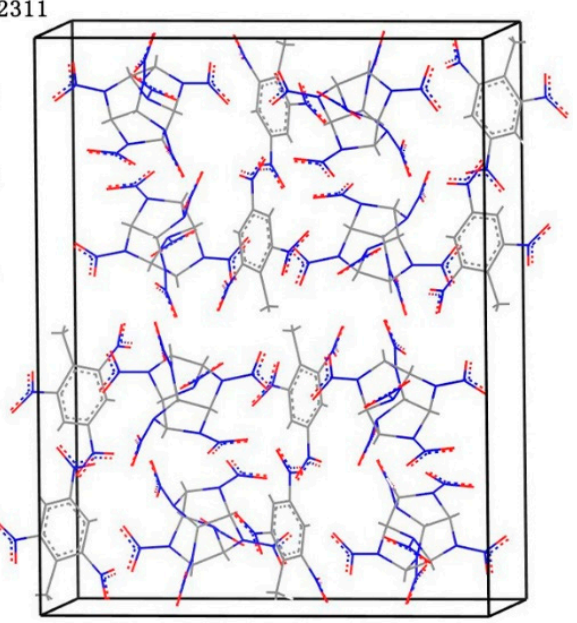

(d) CL-20/TNT

Figure 1. Molecular structures of (a) F2311, (b) CL-20, and (c) TNT. (d) The primitive cell of the CL-20/TNT co-crystal.

The goal of this study is to explore intermolecular interactions and mechanical properties of the CL-20/TNT-based PBXs in different $\mathrm{F}_{2311}$ contents using molecular dynamics (MD) simulation. This paper is arranged as follows. At first, several CL-20/TNT based PBXs in different $\mathrm{F}_{2311}$ content were constructed. Then, we performed MD simulations to study interactions between CL-20/TNT and $\mathrm{F}_{2311}$ and the mechanical properties of PBXs. Pair correlation function (PCF) was used to explore the interface structures between the co-crystal explosive and the polymer binders. Binding energy $\left(E_{\text {bind }}\right)$ can provide information about interfacial reaction and thermal stability. More specifically, $\mathrm{N}-\mathrm{NO}_{2}$ trigger bond lengths of CL-20 were discussed in terms of the relationship with sensitivity. In addition, the mechanical properties such as tensile modulus $(E)$, bulk modulus $(K)$, shear modulus $(G)$, Poisson's ratio $(v)$ and Cauchy pressure $\left(C_{12}-C_{44}\right)$ were also calculated, and both are discussed in this paper. 


\section{Models and Computational Methods}

All simulations were conducted utilizing the condensed-phase optimized molecular potentials for atomistic simulation studies (COMPASS) force field [29], which is suitable for simulations of nitro-compound explosives and their PBXs, and is suitable for calculating of interfacial interactions between different components in PBXs [30-32]. The primitive CL-20/TNT co-crystal cell [16] derived from X-ray diffraction contains 8 CL-20 molecules and 8 TNT molecules. Based on the co-crystal cell, the primary cell of CL-20/TNT corresponding to $6(3 \times 2 \times 1)$ unit cells were built. We built four $F_{2311}$ molecular chains, which contain 10, 36, 62 and 88 constitutional repeating units, respectively. Additionally, the corresponding amorphous $\mathrm{F}_{2311}$ cells were obtained by using the high-low pressure dynamics simulation method [33]. The procedure of building PBXs models were as follows. For the crystalline surfaces $\left(\begin{array}{lll}1 & 0 & 0\end{array}\right)$ of the CL-20/TNT cocrystal $(3 \times 2 \times 1)$ unit cells, the $c$ lattice length was $43.40 \AA$, and the corresponding interface, $a \times b$, was $26.74 \AA \times 24.70 \AA$. Then, the corresponding interface, $a \times b$, of the $\mathrm{F}_{2311}$ cells was changed to $26.74 \AA \times 24.70$ $\AA$; the size $a \times b$ was kept unchanged; $c$ lattice lengths of fluoropolymer box step-by-step were resized until the $\mathrm{F}_{2311}$ theoretical density was reached; each step of the adjustment needs the molecular dynamics simulation running to equilibrium state. Then, PBXs models were made by merging $\mathrm{F}_{2311}$ fluoropolymer on the $\left(\begin{array}{lll}1 & 0 & 0\end{array}\right)$ crystalline surface of CL-20/TNT. Therefore, there are four PBXs models shown in Figure 2. The weight percentages of the $\mathrm{F}_{2311}$ in the PBXs models are $2.5 \%, 9.2 \%, 14.9 \%$ and $19.9 \%$, respectively.

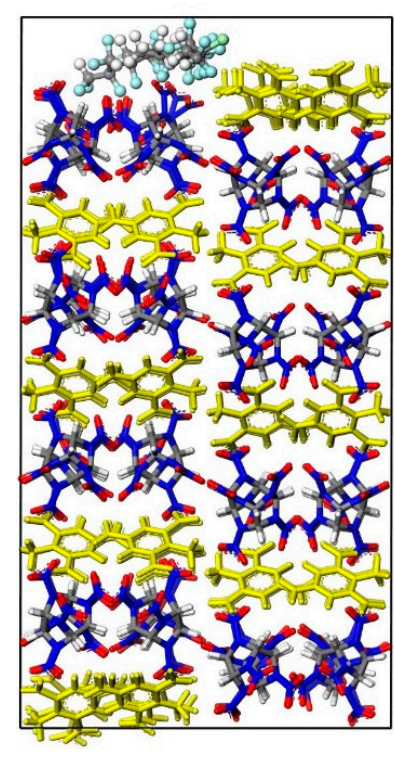

(a)

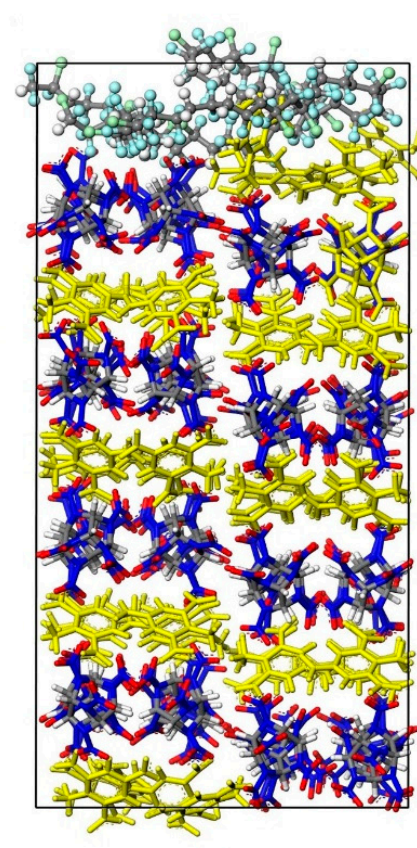

(b)

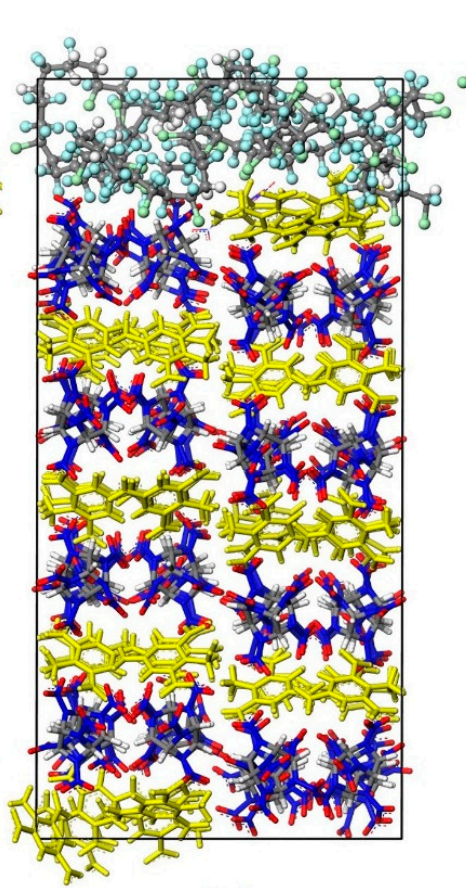

(c)

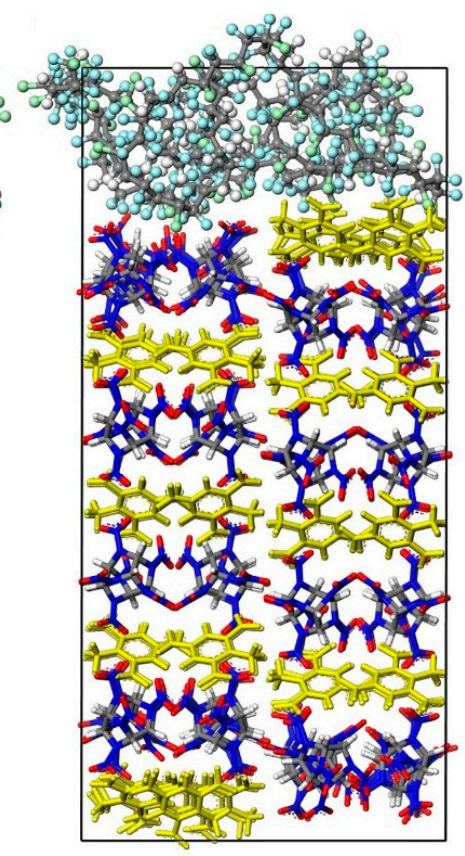

(d)

Figure 2. PBXs models with $\mathrm{F}_{2311}$ content (a) 2.5\%, (b) 9.2\%, (c) 14.9\%, (d) 19.9\% (CL-20 in stick model, TNT in yellow and $\mathrm{F}_{2311}$ in Ball model).

All the models were allowed to evolve dynamically in isothermal-isobaric (NPT) ensemble at $300 \mathrm{~K}$ and atmospheric pressure, in which the temperature was maintained through the Andersen stochastic collision method [34] and the pressure was controlled via the Parrinello-Rahman [35] scheme with all cell parameters fully relaxed at atmospheric pressure. The van der Waals (vdW) interactions were truncated at $9.5 \AA$ with long range tail correction, and the electrostatic interactions were calculated via the standard Ewald summation. The equations of motion were integrated with a step of $1 \mathrm{fs}$. Equilibration run was performed for $5 \mathrm{~ns}$, which is referred to the equilibrium at the new state by 
running for a period for the simulating model and should be extended at least until the instantaneous values of the potential energy and temperature, etc., for the simulating model have ceased to show a systematic drift and have started to oscillate about steady mean values. After equilibration run, production runs of 1 ns were performed, during which data were collected with $10 \mathrm{fs}$ sampling interval for analysis. These computations were all carried out using software Material Studio from Biovia Inc.

\section{Results and Discussions}

\subsection{Binding Energy}

Binding energy $\left(E_{\text {bind }}\right)$ is defined as the negative value of the intermolecular interaction energy $\left(E_{\text {inter }}\right)$. The intermolecular interaction energy between different components can calculate by subtracting individual component energy in the system from the total energy of the whole system [30]. As mentioned above, $E_{\text {bind }}$ between CL-20/TNT and $F_{2311}$ can be evaluated as $E_{\text {bind }}=-E_{\text {inter }}=-\left(E_{\text {total }}-E_{\mathrm{CL}-20 / \mathrm{TNT}}-E_{\mathrm{F} 2311}\right)$, where $E_{\text {total }}$ is the PBXs total energy, $E_{\mathrm{CL}-20 / \mathrm{TNT}}$ and $E_{\mathrm{F} 2311}$ are the energy of CL-20/TNT and $\mathrm{F}_{2311}$, respectively. Binding energy stands for the level of interaction between two components. In this paper, it can reflect the thermal stability of energetic systems and can find out the influence on PBXs with different $\mathrm{F}_{2311}$ contents. $E_{\text {total }}, E_{\mathrm{CL}-20 / \mathrm{TNT}}, E_{\mathrm{F} 2311}, E_{\mathrm{bind}}$ and $E_{\mathrm{bind}}{ }^{\prime}$ are tabulated in Table 1 , where $E_{\text {bind }}{ }^{\prime}$ is the $E_{\text {bind }}$ of unit quantity of $\mathrm{F}_{2311}$ binders.

Table 1. $E_{\mathrm{bind}}, E_{\mathrm{total}}, E_{\mathrm{F} 2311}, E_{\mathrm{CL}-20 / \mathrm{TNT}}$ and $E_{\mathrm{bind}}{ }^{\prime}$ of PBXs in different $\mathrm{F}_{2311}$ contents $^{a}$.

\begin{tabular}{cccccc}
\hline $\begin{array}{c}\mathbf{F}_{2311} \\
\text { Contents }\end{array}$ & $\boldsymbol{E}_{\text {bind }}$ & $\boldsymbol{E}_{\text {total }}$ & $\boldsymbol{E}_{\mathrm{F} 2311}$ & $\boldsymbol{E}_{\mathrm{CL-20/TNT}}$ & $\boldsymbol{E}_{\text {bind }}{ }^{\prime}$ \\
\hline \multirow{2}{*}{$2.5 \%$} & 90.64 & -1309.09 & -325.22 & -1267.50 & 36.25 \\
& $(7.13)$ & $(30.64)$ & $(9.07)$ & $(31.27)$ & $(1.59)$ \\
$9.2 \%$ & 250.95 & -1341.98 & -643.64 & -1252.52 & 27.27 \\
& $(4.47)$ & $(30.82)$ & $(9.16)$ & $(28.65)$ & $(1.26)$ \\
$14.9 \%$ & 281.69 & -1393.27 & -1137.96 & -1251.30 & 18.90 \\
& $(4.59)$ & $(29.36)$ & $(7.25)$ & $(23.24)$ & $(1.43)$ \\
$19.9 \%$ & 356.72 & -1477.70 & -923.94 & -1256.59 & 17.93 \\
& $(6.75)$ & $(29.99)$ & $(7.82)$ & $(31.93)$ & $(1.22)$ \\
\hline
\end{tabular}

${ }^{a}$ Unit: $\mathrm{kcal} \cdot \mathrm{mol}^{-1}$; The corresponding deviations are listed in parenthesis.

Based on the theoretical results shown in Table 1, we can find that the value of $E_{\text {bind }}$ increases with increase in $\mathrm{F}_{2311}$ contents in PBXs, which means that increasing the $\mathrm{F}_{2311}$ content in CL-20/TNT-based PBXs can enhance the interaction between $\mathrm{F}_{2311}$ and CL$20 /$ TNT and the thermodynamic stability of the PBXs. However, it was noticed that the trend of $E_{\text {bind }}$ ' decreases with $\mathrm{F}_{2311}$ contents. Herein, we can find a reasonable explanation from the illustration in Figure 2, where it can be seen that the quantity of uncontacted $F_{2311}$ with CL-20/TNT increased more with increasing of $\mathrm{F}_{2311}$ contents than the quantity of contacted $\mathrm{F}_{2311}$.

\subsection{Pair Correction Function}

The interface structure between CL-20/TNT and $\mathrm{F}_{3211}$ molecular chain was explored by pair correlation function (PCF). PCF gives a measure of probability density $g(\mathrm{r})$ of finding an atom at some distance and thus provides insight into a material structure through revealed local spatial ordering. The PCF curves for different atom pairs in CL20/TNT and $\mathrm{F}_{3211}$ were plotted in Figure 3. The oxygen atoms in CL-20/TNT, nitrogen atom in CL-20/TNT and fluorine atoms in $\mathrm{F}_{2311}$ were labeled as $\mathrm{O}, \mathrm{N}$ and F, respectively, while hydrogen atoms in $\mathrm{F}_{2311}$ and CL-20/TNT were labeled as $\mathrm{H} 1$ and $\mathrm{H} 2$, respectively. 


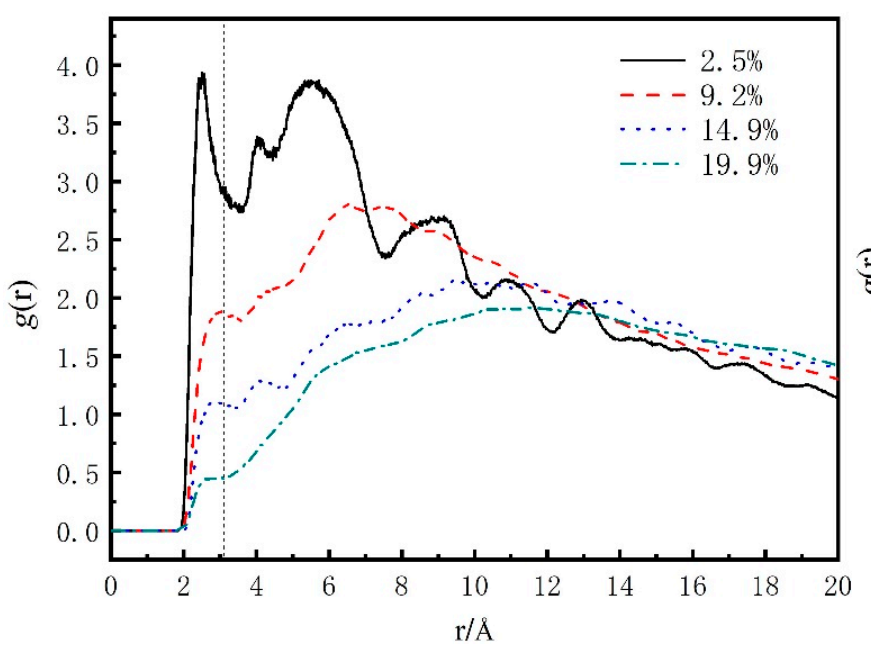

(a) $\mathrm{H}_{2} \cdots \mathrm{F}$

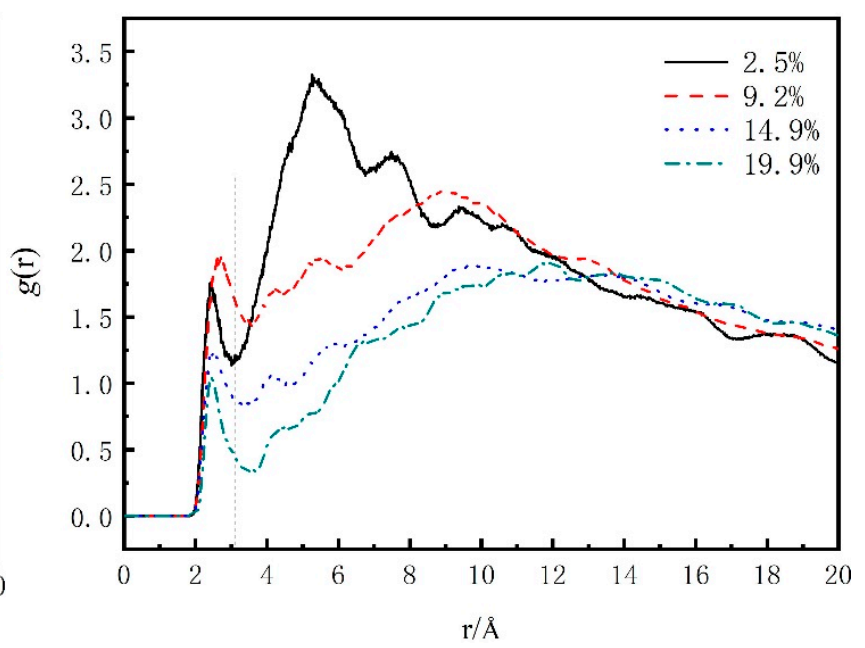

(b) $\mathrm{H}_{1} \cdots \mathrm{O}$

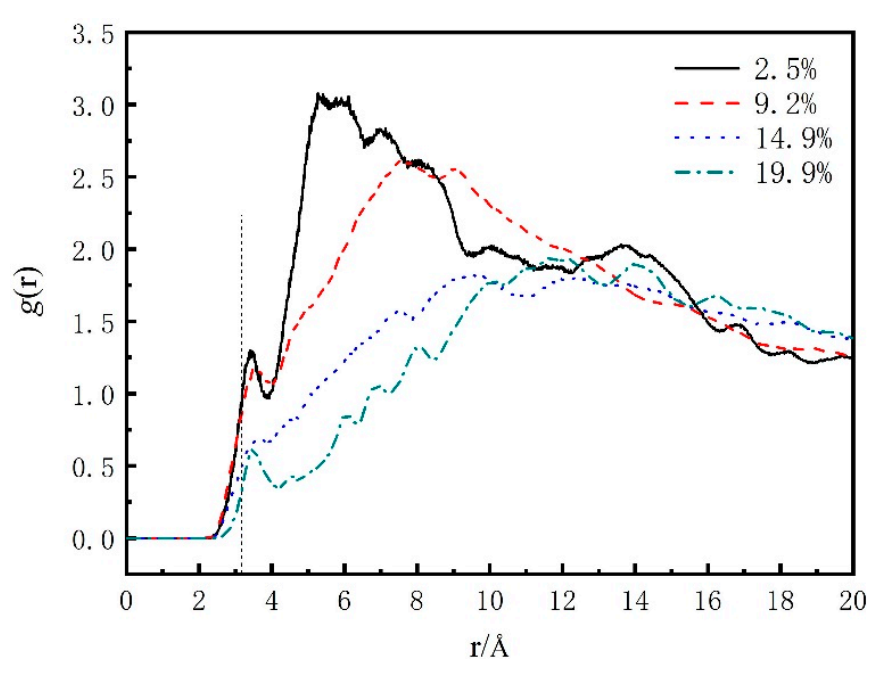

(c) $\mathrm{H}_{1} \cdots \mathrm{N}$

Figure 3. PCF for atom pairs in CL-20/TNT-based PBXs, (a) $\mathrm{H}_{2} \cdots \mathrm{F},(\mathbf{b}) \mathrm{H}_{1} \cdots \mathrm{O},(\mathbf{c}) \mathrm{H}_{1} \cdots \mathrm{N}$.

Generally the interaction distance range for hydrogen bond is $2.0-3.1 \AA$, and the distance range for stronger $\mathrm{vdW}$ and electrostatic interactions is 3.1-5.0 $\AA$. When the distance between two atoms is farther than $5.0 \AA$, the vdW interaction is quite weak. From Figure $3 a, b$, it was found that in hydrogen bond range, the PCF curves all give comparatively high peaks, indicating that the hydrogen bonds exist in $\mathrm{H}_{2} \cdots \mathrm{F}$ pairs and $\mathrm{H}_{1} \cdots \mathrm{O}$ pairs of $\mathrm{F}_{2311}$ molecules and CL-20/TNT. Additionally, the peaks vary in intensity with $\mathrm{F}_{2311}$ content. From Figure $3 \mathrm{a}$, we can find that the $g(\mathrm{r})$ value of low $\mathrm{F}_{2311}$ content is mostly larger than high $\mathrm{F}_{2311}$ content. Similarly, the trend of $g(\mathrm{r})$ value in Figure $3 \mathrm{~b}$ is almost the same, but largest value for hydrogen bonds is $9.2 \% \mathrm{~F}_{2311}$ content. Figure 4 gives a visual representation of hydrogen bonding interactions of $\mathrm{H}_{1} \cdots \mathrm{O}$ and of $\mathrm{H}_{2} \cdots \mathrm{F}$ for $2.5 \%$ $\mathrm{F}_{2311}$ content, for example. For $\mathrm{H}_{1} \cdots \mathrm{N}$ in Figure $3 \mathrm{c}$, the curve has a comparatively high peak only in the vdW interaction range, implying only $\mathrm{vdW}$ and electrostatic interactions exist between $\mathrm{H}_{1} \cdots \mathrm{N}$. 


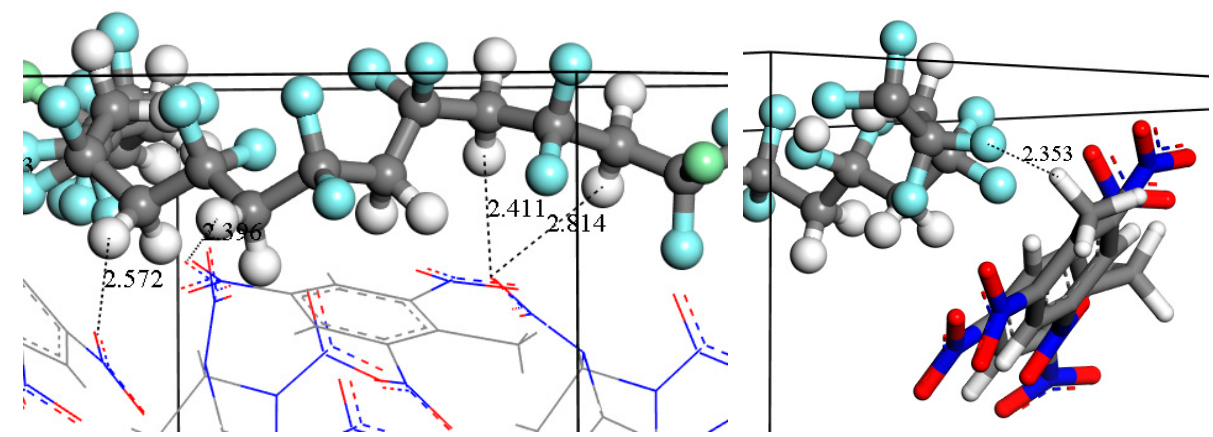

(a)

(b)

Figure 4. Illustration of hydrogen bonds of (a) O atoms in the co-crystal (red line model) with $\mathrm{H}$ atoms in $\mathrm{F}_{2311}$ (white ball) and (b) $\mathrm{H}$ atoms in the co-crystal (white stick) with $\mathrm{F}$ atoms in $\mathrm{F}_{2311}$ (pale blue ball).

\section{3. $\mathrm{N}-\mathrm{NO}_{2}$ Trigger Bond Length}

For energetic compounds, there exists a criterion to theoretically judge the relative sensitivity [22]. According to Principle of Smallest Bond Order (PBSO) based on quantum chemical calculation, for a series of energetic compounds with smaller bond order of trigger bond in molecular means the compound is more sensitive [36,37]. This principle has been used extensively in the prediction of impact sensitivity for various types of energetic compounds. Classical MD simulation does not provide electronic structure, and cannot give the bond order data. However, MD simulation can provide statistical distribution of bond length instead of the bond order data. Usually, chemical bond length can be characterized by the bond order and bond length in molecular. Thus it is suitable to evaluate sensitivity based on the molecular structure parameter, bond length, obtained through MD simulation.

We all know that the $\mathrm{N}-\mathrm{NO}_{2}$ bond is a trigger bond of nitramine explosives. Additionally, it is well know that CL-20 is more sensitive than TNT, and the CL-20 component in CL-20/TNT is prior to decompose in detonation. Therefore, in this work, the $\mathrm{N}^{-\mathrm{NO}_{2}}$ bond in CL-20 is chosen as the trigger bond. Table 2 presents the results of trigger bond $\left(\mathrm{N}^{-} \mathrm{NO}_{2}\right)$ lengths of CL-20 component in PBXs at different $\mathrm{F}_{2311}$ contents. When the bond length is longer, the bond is fractured more easily, which makes CL-20 molecules more active and decompose more easily. It can be found from Table 2 that the average bond lengths $L_{\text {ave }}$ of all the models are almost unchanged, but the maximum bond length $\left(L_{\max }\right)$ of trigger bond has more obvious change with $\mathrm{F}_{2311}$ content increasing, which means that $L_{\max }$ of the trigger bond is more tightly correlated to the initial bond fractured in PBXs' detonation. As the content increases, the maximum bond length decreases gradually. When the content of $\mathrm{F}_{2311}$ rose to $9.2 \%$, the $L_{\max }$ decreased from $1.5972 \AA$ to $1.5817 \AA$. After that, the $L_{\max }$ changed slightly, basically maintaining the level of $9.2 \%$. The change is consistent with the fact that energetic material becomes less sensitive as $\mathrm{F}_{2311}$ content increases. Hence, using $L_{\max }$ to measure the sensitivity of energetic is efficient. Additionally, we can find that when the content of $F_{2311}$ reaches $9.2 \%$, continuous increase of the $F_{2311}$ content has less effect on the sensibility.

Table 2. The trigger bond $\left(\mathrm{N}-\mathrm{NO}_{2}\right)$ lengths $(\AA)$ of $\mathrm{CL}-20$ at different $\mathrm{F}_{2311}$ contents ${ }^{a}$.

\begin{tabular}{cccccc}
\hline Content & $\mathbf{0 . 0} \%$ & $\mathbf{2 . 5 \%}$ & $\mathbf{9 . 2} \%$ & $\mathbf{1 4 . 9 \%}$ & $\mathbf{1 9 . 9 \%}$ \\
\hline$L_{\text {ave }}$ & 1.3927 & 1.3935 & 1.3936 & 1.3932 & 1.3934 \\
& $(0.028)^{a}$ & $(0.028)$ & $(0.031)$ & $(0.030)$ & $(0.030)$ \\
$L_{\max }$ & 1.5972 & 1.5843 & 1.5817 & 1.5816 & 1.5817 \\
\hline
\end{tabular}

$\bar{a}$ The corresponding deviations for $L_{\text {ave }}$ are listed in parenthesis. 


\subsection{Mechanical Properties}

Mechanical properties are the most important properties of energy materials, because they are related to the preparation, storage, transportation and usage of materials. Elastic modulus is the index of a material's stiffness, and it is also the measurement of a material's resistance to elastic deformation. The plasticity and fracture properties can be related to the elastic modulus. Higher shear modulus means higher stiffness and shear strength, reflecting resistance to shearing strain $[23,38,39]$. Higher bulk modulus means higher rupture strength, that is, the greater the value of $K$ is, the more energy will be required for a material to rupture $[31,40,41]$. Cauchy pressure $\left(C_{12}-C_{44}\right)$ can reflect the brittle/ductile behavior of a material. The high value of Cauchy pressure $\left(C_{12}-C_{44}\right)$ is related to ductility, and the low value is related to brittleness. When a material is compressed in one direction, it usually tends to expand in the other two directions perpendicular to the direction of compression. Poisson's ratio is a measure of this effect.

Based on the fluctuation analysis of the production trajectories and Reuss average [42] of the co-crystal model (without $\mathrm{F}_{2311}$ binder) and its corresponding PBXs models, the calculated tensile modulus $(E)$, bulk modulus $(K)$, shear modulus $(G)$, Poisson's ratio $(v)$, Cauchy pressure $\left(C_{12}-C_{44}\right)$ are listed Table 3 . As we can see from Table 3, E, K and $G$ reduced gradually with the increase of $\mathrm{F}_{2311}$ content, indicating that the stiffness of the PBXs decreases. Additionally, it can be found that the polymer addition has less effect on Poisson's ratio. The Cauchy pressure $\left(C_{12}-C_{44}\right)$ values increase with $F_{2311}$ content increasing, which can be deduced that the ductility of the Cl-20/TNT based PBXs increases with increasing $\mathrm{F}_{2311}$ content. Generally, less stiffness and better ductility for PBXs compared to CL-20/TNT means it is easier to deplete and disperse partially the external stimulus energy imposed on them during loading and transportation, which can reduce possibility of hot spots, and thus has lower sensitivity.

Table 3. Tensile modulus $(E)$, bulk modulus $(K)$, shear modulus $(G)$, Poisson's ratio $(v)$ and Cauchy pressure $\left(C_{12}-C_{44}\right)$ for the PBXs models with different $F_{2311}$ contents ${ }^{a}$.

\begin{tabular}{cccccc}
\hline Content & $\mathbf{0 . 0} \%$ & $\mathbf{2 . 5} \%$ & $\mathbf{9 . 2} \%$ & $\mathbf{1 4 . 9 \%}$ & $\mathbf{1 9 . 9 \%}$ \\
\hline$E$ & $6.22(0.03)$ & $5.38(0.05)$ & $4.32(0.06)$ & $4.11(0.03)$ & $3.65(0.02)$ \\
$K$ & $7.49(0.04)$ & $6.41(0.10)$ & $5.22(0.12)$ & $5.02(0.07)$ & $4.54(0.04)$ \\
$G$ & $1.88(0.02)$ & $1.54(0.03)$ & $1.34(0.07)$ & $1.36(0.02)$ & $1.33(0.02)$ \\
$v$ & $0.38(0.02)$ & $0.39(0.00)$ & $0.38(0.00)$ & $0.38(0.00)$ & $0.37(0.00)$ \\
$C_{12}-C_{44}$ & $1.79(0.11)$ & $2.81(0.11)$ & $2.78(0.16)$ & $3.07(0.13)$ & $3.42(0.11)$ \\
\hline
\end{tabular}

${ }^{a}$ The corresponding deviations are listed in parenthesis. The units for $E, K$ and $G$ are GPa.

\section{Conclusions}

In this study, we performed a NPT-MD simulations of CL-20/TNT-based PBXs with $\mathrm{F}_{2311}$ as polymeric binders. The simulations involved binding energy calculation and PCF analysis for the thermal stability evaluation and the interfacial structure exploration between the co-crystal and $\mathrm{F}_{2311}$, the maximum bond length of the $\mathrm{N}-\mathrm{NO}_{2}$ trigger bond and mechanical property computation. These studies are in favor of theoretical research and practical applications of the co-crystal.

From the calculated binding energies, $E_{\text {bind }}$ between $\mathrm{F}_{2311}$ and Cl-20/TNT increases with the increasing content of $\mathrm{F}_{2311}$, but $E_{\text {bind }}$ of unit quantity of $\mathrm{F}_{2311}$ binders reduces due to the specific surface area of $\mathrm{F}_{2311}$ contacted CL-20/TNT. Therefore, the interaction between the binder and the explosive can be improved by increasing the contact area of binder and explosive. PCF analysis of atom pairs in the interfacial structure has indicated that hydrogen bond exists between CL-20/TNT and $\mathrm{F}_{2311}$. Additionally, the hydrogen bond mainly came from $\mathrm{H} 1 \cdots \mathrm{O}$ and of $\mathrm{H} 2 \cdots \mathrm{F}$. By analyzing the maximum bond length of $\mathrm{N}-\mathrm{NO}_{2}$ trigger bond, it can be found that increasing $\mathrm{F}_{2311}$ content can decrease the sensitivity of CL-20/TNT based PBXs, but a continuous increase in the $\mathrm{F}_{2311}$ content has less effect on the sensibility when the content of $\mathrm{F}_{2311}$ reaches $9.2 \%$. The mechanical properties shows that as the $\mathrm{F}_{2311}$ content increases, the moduli of CL-20/TNT-based PBXs decrease, but the 
ductility was improved. To sum up, the small amount of polymer binders $\mathrm{F}_{2311}$ coating with the CL-20/TNT co-crystal makes the PBXs more insensitive and give them better mechanical properties.

Author Contributions: Conceptualization, S.L. and J.X.; methodology, S.L.; formal analysis, S.L.; investigation, S.L.; writing—original draft preparation, S.L.; writing—review and editing, J.X.; visualization, S.L.; supervision, J.X.; funding acquisition, J.X. All authors have read and agreed to the published version of the manuscript.

Funding: The research was funded by the grant from the National Natural Science Foundation of China (Grant No. 11572160).

Institutional Review Board Statement: Not applicable.

Informed Consent Statement: Not applicable.

Data Availability Statement: All data are contained within the article.

Acknowledgments: The authors would like to thank the grant from the National Natural Science Foundation of China (Grant No. 11572160).

Conflicts of Interest: The author declares no conflict of interest.

Sample Availability: Samples of the compounds used in this study are available from the authors.

\section{References}

1. Xiao, H.M.; Xu, X.J.; Qiu, L. Theoretical Design of High. Energy Density Materials; Science Press: Beijing, China, 2008.

2. Xiao, J.J.; Zhu, W.H.; Zhu, W.; Xiao, H.M. Molecular Dynamics of Energetic Materials; Science Press: Beijing, China, 2013.

3. Sikder, A.K.; Sikder, N. A review of advanced high performance, insensitive and thermally stable energetic materials emerging for military and space applications. J. Hazard. Mater. 2004, 112, 1-15. [CrossRef]

4. Agrawal, J.P. Recent trends in high-energy materials. Prog. Energy Combust. Sci. 1998, 24, 1-30. [CrossRef]

5. Huang, X.; Zhao, X.; Long, X.; Dai, X.; Zhang, K.; Li, M.; Guo, F.; Qiao, Z.; Wen, Y. Comparison Study of Carbon Clusters Formation during Thermal Decomposition of 1,3,5-triamino-2,4,6-trinitrobenzene and Benzotrifuroxan: A ReaxFF based Sequential Molecular Dynamics Simulation. Phys. Chem. Chem. Phys. 2020, 22, 5154-5162. [CrossRef]

6. CHOI, C.S.; BOUTIN, H.P. A Study of the Crystal Structure of $\beta$-cyclotetramethylene Tetranitramine by Neutron Diffraction. Acta Cryst. B 1970, 26, 1235-1240. [CrossRef]

7. Li, H.; Shu, Y.; Gao, S.; Chen, L.; Ma, Q.; Ju, X. Easy methods to study the smart energetic TNT/CL-20 co-crystal. J. Mol. Model. 2013, 19, 4909-4917. [CrossRef]

8. Pang, W.Q.; Wang, K.; Zhang, W.; Luca, L.T.; Fan, X.Z.; Li, J.Q. CL-20-Based Cocrystal Energetic Materials: Simulation, Preparation and Performance. Molecules 2020, 25, 4311. [CrossRef]

9. Jia, Q.; Lei, D.; Zhang, S.; Zhang, J.; Liu, N.; Kou, K. Solubility Measurement and Correlation for HNIW·TNT Co-crystal in Nine Pure Solvents from T $=(283.15$ to 318.15) K. J. Mol. Liq. 2021, 323, 114592. [CrossRef]

10. Liu, H.; Li, Q.K.; He, Y.H. Pyrolysis of CL20-TNT Cocrystal from ReaxFF/lg Reactive Molecular Dynamics Simulations. Acta Phys. Sin. Chin. Ed. 2013, 62, 208202. [CrossRef]

11. Sha, Y.; Zhang, X. Impact sensitivity and moisture adsorption on the surface of CL-20/TNT cocrystal by molecular dynamics simulation. Appl. Surf. Sci. 2019, 483, 91-97. [CrossRef]

12. Zhu, S.; Ji, J.; Zhu, W. Intermolecular Interactions, Vibrational Spectra, and Detonation Performance of CL-20/TNT Cocrystal. J. Chin. Chem. Soc. 2020, 67, 1742-1752. [CrossRef]

13. Bao, L.; Lv, P.; Fei, T.; Liu, Y.; Sun, C.; Pang, S. Crystal structure and explosive performance of a new CL-20/benzaldehyde cocrystal. J. Mol. Struct. 2020, 1215, 128267. [CrossRef]

14. Chen, P.Y.; Zhang, L.; Zhu, S.G.; Cheng, G.B. Theoretical Study of BTF/TNA Cocrystal: Effects of Hydrostatic Pressure and Temperature. Def. Technol. 2015, 11, 132-139. [CrossRef]

15. Liu, G.R.; Wei, S.H.; Zhang, C.Y. Review of the Intermolecular Interactions in Energetic Molecular Cocrystals. Cryst. Growth. Des. 2020, 20, 7065-7079. [CrossRef]

16. Bolton, O.; Matzger, A.J. Improved stability and smart-material functionality realized in an energetic cocrystal. Angew. Chem. Int. Ed. 2011, 50, 8960-8963. [CrossRef] [PubMed]

17. He, Z.; Meng, T.; Wang, Y.; Guo, Z.; Liu, F.; Liu, Z. Effect of 2,4,6-Triamino-3,5-Dinitropyridine-1-Oxide on the Properties of 1,3,5-Trinitro-1,3,5-Triazinane-based PBX Explosives. Propellants Explos. Pyrotech. 2021, 46, 530-536. [CrossRef]

18. Xu, X.J.; Xiao, J.J.; Huang, H.; Li, J.S.; Xiao, H.M. Molecular Dynamics Simulations on the Structures and Properties of $\varepsilon$-CL-20based PBXs. Sci. China Ser. B Chem. 2007, 50, 737-745. [CrossRef]

19. Liu, B.; Gao, P.; Li, S.s.; Xiao, Y.; Xiao, J. Molecular Dynamics Investigation of Adhesion Between CL-20/TNT Co-crystal Surfaces and Adhesives of PLA, PCL, P(LA-co-CL). Chem. J. Chin. Univ. Chin. 2018, 11, 2556-2564. 
20. Zhou, Z.; Chen, P.; Duan, Z.; Huang, F. Study on Fracture Behaviour of a Polymer-Bonded Explosive Simulant Subjected to Uniaxial Compression Using Digital Image Correlation Method. Strain 2012, 48, 326-332. [CrossRef]

21. Dandekar, A.; Koslowski, M. Effect of particle proximity and surface properties on the response of PBX under vibration. Comput. Mater. Sci. 2021, 192, 110334. [CrossRef]

22. Xiao, J.J.; Wang, W.R.; Chen, J.; Ji, G.F.; Zhu, W.; Xiao, H.M. Study on Structure, Sensitivity and Mechanical Properties of HMX and HMX-based PBXs with Molecular Dynamics Simulation. Comput. Theor. Chem. 2012, 999, 21-27. [CrossRef]

23. Cao, Q.; Xiao, J.J.; Gao, P.; Li, S.S.; Zhao, F.; Wang, Y.A.; Xiao, H.M. Molecular dynamics simulations for CL-20/TNT co-crystal based polymer-bonded explosives. J. Theor. Comput. Chem. 2017, 16, 1750072. [CrossRef]

24. Mares, J.O.; Miller, J.K.; Sharp, N.D.; Moore, D.S.; Adams, D.E.; Groven, L.J.; Rhoads, J.F.; Son, S.F. Thermal and mechanical response of PBX 9501 under contact excitation. J. Appl. Phys. 2013, 113, 084904. [CrossRef]

25. Asay, B. Shock Wave Science and Technology Reference Library; Springer: Heidelberg, Germany, 2009.

26. Yang, Y.; Li, X.; Zhao, Y.; Han, Y.; Sun, Y.; Wang, J. Preparation and characterization of core-shell structured FOX-7/F2602 PBX with improved thermal stability and reduced sensitivity. AIP Adv. 2021, 11, 025323. [CrossRef]

27. Peiris, S.M.; Piermarini, G.J. Static Compression of Energetic Materials; Springer: Berlin/Heidelberg, Germany, 2008.

28. Liu, J.H.; Yang, Z.J.; Liu, S.J.; Zhang, J.H.; Liu, Y.G. Effects of Fluoropolymer Binders on the Mechanical Properties of TATB-Based PBX. Propellants Explos. Pyrotech. 2018, 43, 664-670. [CrossRef]

29. Sun, H. COMPASS: An Ab Initio Force-Field Optimized for Condensed-Phase Applications-Overview with Details on Alkane and Benzene Compounds. J. Phys. Chem. B 1998, 102, 7338-7364. [CrossRef]

30. Sun, T.; Xiao, J.J.; Ji, G.; Zhao, F.; Xiao, H. Molecular Dynamics Simulation Studies of the CL-20/DNB Co-crystal. Cent. Eur. J. Energ. Mat. 2016, 13, 677-693. [CrossRef]

31. Xu, X.; Xiao, J.; Huang, H.; Li, J.; Xiao, H. Molecular Dynamic Simulations on the Structures and Properties of Epsilon-CL-20(0 0 1)/F2314 PBX. J. Hazard. Mater. 2010, 175, 423-428. [CrossRef]

32. Fu, J.; Wang, B.; Chen, Y.; Li, Y.; Tan, X.; Wang, B.; Ye, B. Computational analysis the relationships of energy and mechanical properties with sensitivity for FOX-7 based PBXs via MD simulation. Roy. Soc. Open Sci 2021, 8, 200345. [CrossRef] [PubMed]

33. Ren, H.; Zhang, Q.; Chen, X.; Zhao, W.; Zhang, J.; Zhang, H.; Zeng, R.; Xu, S. A molecular simulation study of a series of cyclohexanone formaldehyde resins: Properties and applications in plastic printing. Polymer 2007, 48, 887-893. [CrossRef]

34. Andersen, H.C. Molecular dynamics simulations at constant pressure and/or temperature. J. Chem. Phys. 1980, 72, 2384-2393. [CrossRef]

35. Martyna, G.J.; Tobias, D.J.; Klein, M.L. Constant Pressure Molecular Dynamics Algorithms. J. Chem. Phys. 1994, 101, 4177-4189. [CrossRef]

36. Xiao, J.J.; Zhao, L.; Zhu, W.; Chen, J.; Ji, G.F.; Zhao, F.; Wu, Q.; Xiao, H.M. Molecular Dynamics Study on the Relationships of Modeling, Structural and Energy Properties with Sensitivity for RDX-based PBXs. Sci. China Chem. 2012, 55, $2587-2594$. [CrossRef]

37. Xiao, H.M.; Wang, Z.X.; Yao, J.M. Quantum Chemical Study on Sensitivity and Stability of Aromatic Nitro Explosives I. Nitro Derivatives of Aminobenzenes. Acta Chim. Sin. 1985, 43, 14-18.

38. Sun, T.; Xiao, J.J.; Liu, Q.; Zhao, F.; Xiao, H.M. Comparative Study on Structure, Energetic and Mechanical Properties of a $\varepsilon$-CL-20/HMX Cocrystal and its Composite with Molecular Dynamics Simulation. J. Mater. Chem. A 2014, 2, 13898. [CrossRef]

39. Hu, Q.M.; Yang, R. Mechanical properties of structural materials from first-principles. Curr. Opin. Solid State Mater. Sci. 2006, 10, 19-25. [CrossRef]

40. Xiao, Y.Q.; Sun, T.; Li, S.S.; Xiao, J.J. Molecular Dynamics Simulation Studies of the CL-20/DNB Co-crystal Based PBX with HTPB. J. Phys. Conf. Ser. 2021, 1721, 012010. [CrossRef]

41. Xu, X.J.; Xiao, H.M.; Xiao, J.J.; Zhu, W.; Huang, H.; Li, J.S. Molecular Dynamics Simulations for Pure $\varepsilon$-CL-20 and $\varepsilon$-CL-20-based PBXs. J. Phys. Chem. B 2006, 110, 7203-7207. [CrossRef]

42. Parrinello, M.; Rahman, A. Strain Fuctuation and Elastic Constants. J. Chem. Phys. 1982, 76, 2662-2666. [CrossRef] 